\title{
La Suède, championne de l'action pour le développement
}

Écrit par : Anna Chapman, L'Observateur de l'OCDE

Dernière mise à jour : 2 mars 2020

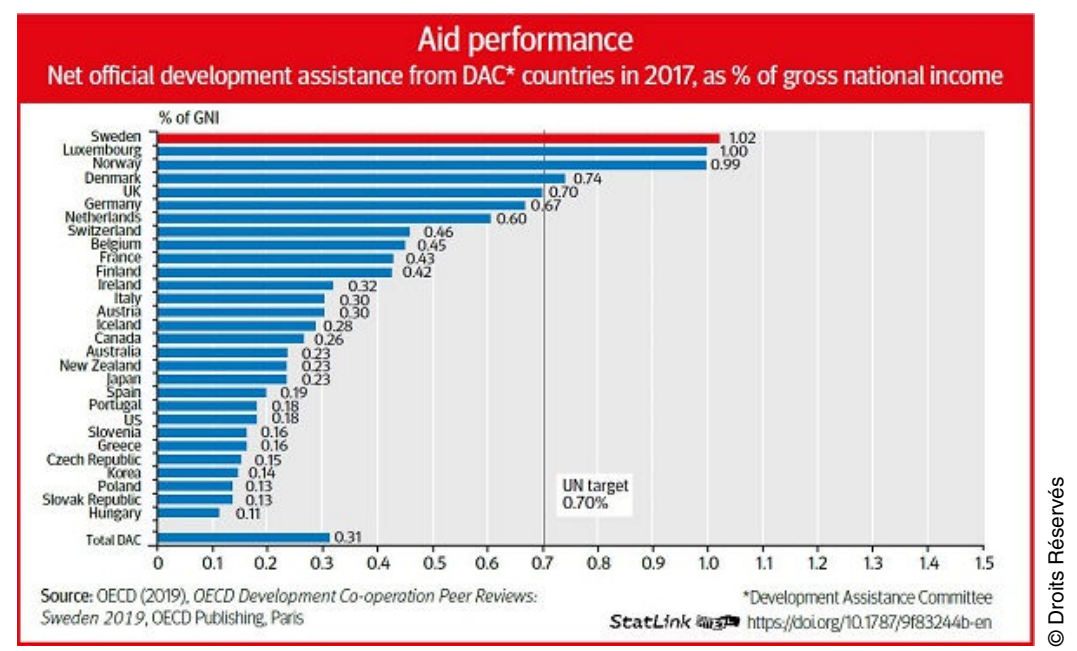

Depuis 2006, la Suède a alloué $1 \%$ de son revenu national brut (RNB) à l'aide publique au développement (APD). En 2017, elle était, en pourcentage du RNB, le plus grand fournisseur d'APD parmi les pays du Comité d'aide au développement de l'OCDE, dépassant l'objectif de $0.7 \%$ fixé par les Nations Unies.

Comment y parvient-elle ? Tant la population que les autorités adhèrent fortement aux engagements du pays en matière de développement, adhésion renforcée par les activités de sensibilisation menées par le ministère des Affaires étrangères et l'Agence suédoise de coopération internationale au développement.

Malgré la montée des inégalités de revenus, le manque de logements et l'augmentation des prix de l'immobilier résidentiel, la Suède reste un pays ouvert, qui a à cœur d'aider ceux qui subissent persécutions et violences tout comme ceux qui les fuient. En 2015, la Suède a accueilli 163000 demandeurs d'asile, ce qui fait d'elle le premier pays d'accueil de l'OCDE au regard de sa population.

La Suède continue de déployer une action humanitaire efficace et s'appuyant sur des principes ; elle met en œuvre une approche coordonnée pour prendre en compte l'articulation entre développement, action humanitaire et recherche de la paix dans les contextes fragiles et les situations de crise. En outre, elle a consacré, 
en 2017, plus de $87 \%$ de son aide bilatérale ventilable à des projets ayant pour objectif principal ou significatif l'égalité femmes-hommes et l'autonomisation des femmes.

Cependant, comme le montre le dernier examen par les pairs que le CAD a consacré à la Suède, cette dernière peut encore améliorer son action en faveur du développement en remédiant au manque de personnel interne et en renforçant son cadre stratégique de coopération pour le développement et d'action humanitaire. Alors que son aide est actuellement saupoudrée sur de nombreux partenaires, un recentrage de ses activités sur un plus petit nombre de pays permettrait à la Suède d'accroître encore son impact et d'alléger la pression qui s'exerce sur le personnel concerné.

\section{Références}

La Suède, championne de l'action pour le développement http://dx.doi.org/ https://doi.org/10.1787/9f83244b-en 